\title{
A liberdade humana e as suas diferentes situações existenciais: a infância, o sono, a demência e a ignorância no pensamento de Luis de Molina (1535-1600)
}

\begin{abstract}
Human freedom and its different existential situations: infancy, sleep, insanity and ignorance according to Luis de Molina (1535-1600)
\end{abstract}

* João Rebalde

\begin{abstract}
Resumo: Neste estudo, pretende-se mostrar como o jesuíta Luis de Molina define a liberdade humana e a pensa em diferentes situações existenciais, nomeadamente a infância, o sono, a demência e a ignorância, na obra Concordia liberi arbitrii cum gratiae donis, divina praescientia, providentia, praedestinatione et reprobatione (1588). Discute-se também a importância da educação, da medicina e da religião no desenvolvimento do ser humano, no pensamento de Molina.

Palavras-chave: Luis de Molina. Concordia. Liberdade humana. Infância. Sono. Demência. Ignorância.

Abstract: In this study, we aim to show Luis de Molina's view about human freedom and how it is discussed regarding different existential situations, namely infancy, sleep, insanity and ignorance, in his work Concordia liberi arbitrii cum gratiae donis, divina praescientia, providentia, praedestinatione et reprobatione (1588). We also discuss the significance of education, medicine and religion in the development of human being in Molina's thought.
\end{abstract}

Keywords: Luis de Molina. Concordia. Human freedom. Infancy. Sleep. Insanity. Ignorance.

* Doutorado pela Universidade do Porto e membro do Instituto de Filosofia da Universidade do Porto (Portugal).<jrebalde@gmail.com>. O artigo que agora se edita adapta um capítulo da tese doutoral apresentada à Faculdade de Letras da Universidade do Porto em 2014, intitulada Liberdade humana e perfeição divina. Ciência média e concurso divino na Concordia de Luis de Molina. 
forma como o jesuíta espanhol Luis de Molina define agente livre Ae, como tal, a liberdade humana, na sua controversa obra Concordia liberi arbitrii cum gratiae donis, divina praescientia, providentia, praedestinatione et reprobatione (Lisboa, 1588) ${ }^{1}$, subentende desde logo não apenas uma distinção profunda entre as possibilidades desses agentes e as das causas naturais, mas também entre as diferentes situações existenciais em que se pode encontrar o próprio ser humano.

Nesse contexto, tenhamos em atenção a definição dada pelo autor: "agente livre é aquele que, postos todos os requisitos para atuar, pode atuar e não atuar, ou fazer uma coisa do mesmo modo que a contrária"2.

Comecemos por realçar que, na definição, surgem destacados dois aspetos determinantes: a capacidade de escolha, entendida como posicionamento livre e indiferente diante de um horizonte de possibilidades diversificadas, e o peculiar poder de atuar ou não atuar, de poder afirmar ou negar a ação diante da realidade dada, que guarda o sentido profundo da força do agente livre enquanto tal. Essa capacidade relaciona-se com um outro lado da formulação molinista, a ideia de que a ordem de coisas e circunstâncias em que se encontra o agente convida a uma ação correspondente, estabelecendo-se como disposição que supõe um resultado específico de ação na sua relação com os agentes. É pelo seu papel indeterminado nessa relação que o agente livre se diferencia dos agentes naturais. Ele é aquele que pode diferenciar o resultado da ação para que é convocado, mostrando dessa forma a sua força especificadora e a sua condição peculiar, estabelecendo uma relação indiferente com a ordem de coisas e circunstâncias.

Não obstante a força diferenciadora do agente livre, devemos ter em conta que a liberdade de arbítrio existe sempre sob certas condições constitutivas que determinam as suas possibilidades ${ }^{3}$, sempre no âmbito de uma ordem e circunstancionalidade dadas, o que se explica também pela condição fundamental da natureza da criatura. Trata-se de

1 Neste estudo, usaremos a edição crítica de Johannes Rabeneck: MOLINA, Ludovicus, Liberi arbitrii cum gratiae donis, divina praescientia, providentia, praedestinatione et reprobatione concordia, editionem criticam curavit Iohannes Rabeneck, Oniae - Matriti: Collegium Maximum S. I. - Soc. Edit. "Sapientia", 1953. Recorremos à forma abreviada Concordia para referir e citar esta obra, a partir daquela edição.

2 Cf. MOLINA, Luis de, Concordia, d. 2, 3: "agens liberum dicitur quod positis omnibus requisitis ad agendum potest agere et non agere aut ita agere unum ut contrarium etiam agere possit".

3 Cf. HEVIA ECHEVARRÍA, Juan Antonio, Introdução à Concordia del libre arbitrio con los dones de la gracia y con la presciencia, providencia, predestinación y reprobación divinas, de Luis de Molina, Oviedo: Fundación Gustavo Bueno, 2007, p. 23ss. 
aceitar que as variáveis que se colocam diante da vontade são de certo modo umas e não outras, o que determina sempre de alguma maneira a quantidade e natureza das possibilidades com que se depara o agente, de tal modo que o ato não será apenas determinado por este, mas também pelas próprias alternativas ${ }^{4}$. A determinação acaba por ser a condição indispensável e inalienável da liberdade.

Na definição molinista, confirma-se essa condição, quando se refere

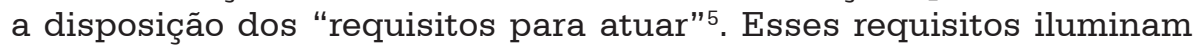
bem a relação entre a determinação inerente à ordem de coisas e circunstâncias e a indeterminação própria da ação do livre arbítrio, sem que a liberdade deixe de ser oposta à necessidade, como bem sublinha Molina $^{6}$. O ser humano pode relacionar-se indiferentemente com as forças externas e internas que o convocam a uma ação determinada. Encontramos um exemplo ilustrativo dessa capacidade no modo como pode negar a comida ou a bebida, estando essas disponíveis, mesmo quando tem fome e sede. A ação humana não é necessitada pelas forças circunstanciais e mantém o poder de atuar indiferentemente em todo o caso. Para que se compreenda melhor essa capacidade, recordemos o que afirma Molina depois de oferecer a definição de agente livre que citamos acima:

Em virtude desta liberdade, a faculdade pela qual este agente pode agir assim, recebe a denominação de livre. Mas, como não age assim, caso não lhe precedam o arbítrio e o juízo da razão, de aqui se segue que, na medida em que recebe previamente este juízo, receba o nome de livre arbítrio. Por este motivo, se em algum lugar devemos situar o livre arbítrio, este não será outro que a vontade, na que formalmente radica a liberdade, que se move antecedida pelo juízo da razão ${ }^{7}$.

Esta passagem é crucial, aclarando as condições e salientando os limites que se podem colocar ao livre arbítrio. Para que esta faculdade esteja presente tem de existir "o arbítrio e o juízo da razão", que permite a distância relativamente ao dispositivo de coisas e circunstâncias,

4 Sobre essa determinação, aqui por nós interpretada e resumida, cf. HEVIA ECHEVARRÍA, Juan Antonio, Introdução à Concordia del libre arbitrio con los dones de la gracia y con la presciencia, providencia, predestinación y reprobación divinas, de Luis de Molina, op. cit., p. 23.

5 Cf. MOLINA, Luis de, Concordia, d. 2, 3.

6 Lembramos que Molina entende sempre a liberdade como oposta à necessidade e é nesse sentido que desenvolve a sua doutrina; cf. MOLINA, Luis de, Concordia, d. 2, 3.

7 Cf. MOLINA, Luis de, Concordia, d. 2, 3: "atque ab hac libertate facultas qua tale agens potest ita operari dicitur libera. Quoniam vero non ita operatur nisi praevio arbitrio iudicioque rationis, inde est, quod quatenus ita praexigit iudicium rationis, liberum appelletur arbitrium. Quod fit ut liberum arbitrium (si alicubi concedendum sit) non sit aliud quam voluntas, in qua formaliter sit libertas explicata praevio iudicio rationis". 
fomentando esse diverso de uma natureza, de um espaço e de um tempo próprios do agente livre, mais além de um estar mergulhado na circunstancialidade e no estado de coisas, permitindo também a reverência da ação a uma finalidade moral. Devemos, no entanto, atender a uma distinção: "o arbítrio e o juízo da razão", isto é, a estrutura de racionalidade devidamente desenvolvida, não é responsável por haver atos livres, é responsável pela afirmação desses atos livres frente à circunstancialidade e por esses se relacionarem e referenciarem decisivamente em termos morais ${ }^{9}$.

Por isso, tudo aquilo que afete o "arbítrio e o juízo da razão", tudo aquilo que afete ou limite a estrutura racional, acaba por ser limitante da mais profunda expressão e consequencialidade moral do livre arbítrio, sem que esteja totalmente em causa um sentido amplo de liberdade ${ }^{10}$. É nesse âmbito que, na Concordia, Molina identifica vários estados nos quais se pode encontrar o ser humano que limitam ou afetam a estrutura racional, considerados como situações existenciais em que não estão reunidas condições para o pleno alcance do livre arbítrio.

Esses estados podem ser variados. Molina destaca a infância, o sono, a demência e a ignorância. Nesses casos, há uma limitação racional importante e consequente, de tal modo que não está presente o adulto e completo uso da razão, capaz de permitir um posicionamento diante da ordem de coisas e circunstâncias e um discernimento no âmbito da moralidade ${ }^{11}$. Não significa, porém, que não haja alguma forma de liberdade, até mesmo de livre arbítrio, assente em um conhecimento elementar das possibilidades, em um poder de escolha e em uma competência deliberativa mínima associada à experiência de utilidade e prazer.

No componente epistolar da obra molinista, encontra-se um valioso contributo para se entender melhor a questão da limitação do livre arbítrio nos diversos estados referidos. Em uma carta escrita por Molina a Francisco Duarte, em abril de $1593^{12}$, encontramos dados importantes sobre essa matéria. O seu conteúdo será incluído na segunda edição de 1595 da Concordia. Nela, o jesuíta espanhol esclarece que esses estados limitantes da racionalidade não suprimem totalmente a liberdade, uma vez que esta não radica na razão, mas na

\footnotetext{
Cf. MOLINA, Luis de, Concordia, d. 2, 3.

Cf. MOLINA, Luis de, Concordia, d. 2, 9.

Cf. MOLINA, Luis de, Concordia, d. 2, 9.

${ }^{11}$ Cf. MOLINA, Luis de, Concordia, d. 2, 4.

12 Cf. STEGMÜLLER, Friedrich, Neue Molinaschriften, Münster: Verlag der Aschendorffschen Verlagsbuchhandlung, 1935 (Beiträge zur Geschichte der Philosophie und Theologie des Mittelalters, Band 32), p. 692ss.
} 
vontade $^{13}$. No caso da infância, o infante menor de oito anos de idade pode realizar uma vasta gama de atos livres e indiferentes, segundo a sua vontade e até razão mínima, possuindo os conhecimentos básicos indispensáveis para que realize alguns atos livremente e dispondo de competências básicas para conhecer de alguma maneira a disposição do estado de coisas e a sua relação com essas:

antes que o entendimento das crianças, no que respeita à sua capacidade reflexiva, esteja suficientemente preparado para discernir entre o bem e o mal morais, na medida necessária para que o ato de volição e de nolição ou também a negação deste ato seja considerado culposo, meritoso ou virtuoso, estaria suficientemente preparado para conhecer quanto seja necessário para que a vontade aja livremente ${ }^{14}$.

Como se entende a partir da citação, há já na criança alguma forma de liberdade, ainda que incompleta, mesmo que a estrutura de racionalidade não esteja ainda totalmente desenvolvida ${ }^{15}$. Basta, para tal, o uso da vontade e a possibilidade inata de realizar atos volitivos livres, além da capacidade para reconhecer o bem e o mal, presentes nas coisas relativamente à utilidade e ao prazer a elas associados em uma dada circunstância. Assim, a vontade acaba por não ser forçada pelo estado de coisas e pela circunstancialidade, podendo agir indiferentemente ${ }^{16}$, ainda que o meio e o contexto tenham uma força assinalável.

A criança tem poder para realizar atos livres, dando com esse poder inato e encontrando ao seu dispor o horizonte de possibilidades com diversas opções. A vontade pode movimentar-se no seio dessas alternativas, apoiando-se em um conhecimento funcional da utilidade e do prazer associado aos objetos, mas esse movimento não é a

${ }_{13}$ Cf. MOLINA, Luis de, Concordia, d. 2, 9: "Ceterum arbitror libertatem esse in voluntate et non in intellectu [...]". Cf. também MOLINA, Luis de, Carta a Francisco Duarte de 1592, in: STEGMÜLLER, Friedrich, Neue Molinaschriften, op. cit., p. 689; Idem, Carta de 1593, in: STEGMÜLLER, Friedrich, Neue Molinaschriften, op. cit., p. 705. Sobre isso, cf. QUERALT, Antonio, Libertad humana en Luis de Molina. Sus elementos constitutivos y posibilidades en un orden natural, in: Archivo Teológico Granadino, Madrid - Granada, 38 (1975), p. 33 e 36s: "la bondad o malicia en su espécie ultima le viene del objeto propuesto por el entendimiento; él la especifica".

${ }^{14}$ Cf. MOLINA, Luis de, Concordia, d. 2, 9: "quod antequam puerorum intellectus ex parte virium sentientium habeat sufficientem dispositionem ad discernendum inter bonum et malum morale, quantum satis est ut ipsorum volitio, nolitio aut continere actum ad culpam vel meritum aut ad virtutem imputentur, habet dispositionem sufficientem ad cognoscendum, quantum satis est ut voluntas libere operetur".Pôr em latim.

15 Cf. OCAÑA GARCÍA, Marcelino, Molinismo y libertad, Córdoba: Publicaciones Obra Social y Cultural Cajasur, 2000, p. 261-262.

16 Atender ao resumo da questão na resposta à carta de Francisco Duarte; cf. MOLINA, Luis de, Concordia, d. 2, 6. 
afirmação da liberdade de uma posição diante do estado de coisas e de circunstâncias com intencionalidade moral refletida. Para haver uma tomada de posição com consequências morais, exige-se necessariamente o papel prévio do juízo da razão, que relaciona a ação com a lei e a moralidade $^{17}$.

Há uma diferença determinante entre o movimento livre da vontade e o ato volitivo ilustrado pelo "arbítrio e juízo da razão", sendo este último a expressão mais profunda e completa do poder do livre arbítrio. No caso particular da criança, pela limitação da capacidade racional, a sua ação não pode ser implicada na lógica da culpa e do mérito ${ }^{18}$.

Transpondo para a definição de livre arbítrio formulada por Molina, podemos dizer que postos todos os requisitos para a ação, que se traduzem em uma certa convocação para uma ação pela circunstância e estado de coisas, a criança pode corresponder ou não, podendo agir de modo indiferente, apesar da tendência para não resistir à disposição circunstancial, especialmente se dificultosa. Recorrendo ao exemplo que propusemos anteriormente, se a criança tiver fome ou sede e se surgir circunstancialmente o objeto capaz de saciar esses apetites, certamente os saciará, ainda que possa realmente não o fazer e realizar o ato contrário, mas não o fará ou deixará de fazer em função de um conhecimento profundo de bem e mal em sentido moral.

De fato, a resposta à carta de Francisco Duarte evidencia que Molina deixa certa autonomia à vontade relativamente à razão, já que, para haver um ato da vontade, basta que se reconheça qualquer bem no objeto em função da utilidade e prazer. Esse bem nunca obriga a vontade a realizar o ato, ainda que a sua influência seja proporcional à intensidade com que se apresente. No caso da ausência da completa e adulta deliberação da razão, a escala da intensidade de bem e mal, no âmbito da utilidade e do prazer, tem uma força significativa sobre a inclinação da vontade. Essa limitação é considerável no contexto dos estados humanos em que a razão não está complemente disponível, mas nunca suprime totalmente a possibilidade de realizar atos livres ${ }^{19}$. Para Molina, há, todavia, uma exceção: a visão de Deus: "a vontade daquele que contempla a Deus nesta vida não pode não amar a Deus"20. E, mais adiante,

17 Cf. OCAÑA GARCÍA, Marcelino, Molinismo y libertad, p. 262.

18 Cf. MOLINA, Luis de, Concordia, d. 2, 4: "Neque ad culpam neque ad meritum eis imputantur, quod non discernant ratione inter bonum et malum morale, quantum satis est ad culpam aut meritum". Cf. também AGOSTINHO DE HIPONA, De Civitate Dei, XXI, 16. Sobre essa questão, cf. BRETT, Annabel S., Changes of State: Nature and Limits of the City in Early Modern Natural Law, Princeton: Princeton University Press, 2011, p. 44ss.

19 Cf. MOLINA, Luis de, Concordia, d. 2, 9.

${ }^{20}$ Cf. MOLINA, Luis de, Concordia, d. 2, 5: "etenim voluntas eius qui Deum inteuter in patria non potest Deum non diligere". 
referindo-se ao bem presente nas coisas: “[...] essa bondade não é tão grande e de conhecimento tão profundo que provoque uma necessidade à vontade, como sucede com todas as bondades, exceto com a visão pura de Deus $[\ldots] " 21$.

A ideia do jesuíta está em linha com as palavras de Tomás de Aquino, quando defende que a vontade não é necessitada por nenhum objeto, exceto pela certeza da visão de Deus ${ }^{22}$. Mas, nesse extremo absoluto do bem, está já presente esse outro sentido de liberdade, mais além de uma oposição entre liberdade e necessidade, a realização do ato de "liberdade pleno e perfeito" ${ }^{23}$, a liberdade verdadeira, completa e perfeita em Deus.

Nos restantes estados apontados pelo autor, como é o caso da demência e do sono, embora com as devidas diferenças, as consequências acabam por ser as mesmas que na infância. Nesse sentido, é interessante o caso da demência, que o autor aborda procurando o conhecimento das ciências do seu tempo ${ }^{24}$ e com um assinalável acento moderno. Encara-a como uma doença e incapacidade física que acaba por alterar as funções racionais normais, mas que não transforma definitivamente a natureza profunda do ser humano, sendo um estado transitório e circunstancial que pode ser ultrapassado pela medicina. Entre os pólos, por um lado, de um estado anterior à demência e, por outro, da hipotética cura, situase a doença que limita o perfeito uso da razão, sem que suspenda por completo essa liberdade inata da vontade, que permanece capaz de realizar alguns atos livres, de modo mais ou menos completo, consoante a capacidade racional disponível.

O caso do sono é essencialmente diferente, mas as implicações desse estado acabam por ser do mesmo teor do anterior. A sucessão entre o sono e a vigília engendra uma dupla face do uso da racionalidade. A vigília é, para Molina, o estado próprio do uso completo e consequente da razão, enquanto o sono limita esse uso, afetando a capacidade de discernimento e desresponsabilizando o agente livre pelas consequências morais dos seus atos ${ }^{25}$. A sensibilidade a essa dupla face, tão bem aclarada e

${ }^{21}$ Cf. MOLINA, Luis de, Concordia, d. 2, 9: "ea vero bonitas si tanta non site et tam perspicue cognita quae voluntati necessitatem inferat, ut nulla est talis praeter Deum clare visum, integrum est voluntati non elicere actum [...]".

22 Cf. THOMAS DE AOUINO Summa theologiae I, q. 82, a. 2: "sed voluntas videntes Deum per essentiam, de necessitate inhaeret Deo, sicut nunc ex necessitate volumus esse beati".

${ }^{23}$ Cf. MOLINA, Luis de, Concordia, d. 2, 5: "plenae et perfectae libertatis".

24 Cf. MOLINA, Luis de, Concordia, d. 2, 12.colocar o que pensa São Tomás de Aquino e incluir nesta nota de rodapé a obra secundária sobre este conhecimento científico e seu uso no tempo de Molina.

25 Cf. MOLINA, Luis de, Concordia, d. 2, 12. 
delimitada pelo jesuíta espanhol, leva-nos a uma marginal e ensaística lembrança de um autor mais tardio, como é o caso de Friedrich Nietzsche, nos temas trágicos do século $19^{26}$. A dupla face apolínea e dionisíaca, personificações dessa dualidade diurna e noturna, desdobrada na contraposição de racional e irracional, moral e amoral, que imparável e inseparavelmente sucedem no ser humano, parece encontrar-se com o pensamento do jesuíta espanhol, nessa consciência de que o ser humano não pode segurar as rédeas morais da sua ação, compreendendo limites no uso da razão, nesses terrenos necessários do sono, do corpo e da consciência. O sono impõe-se, assim, como necessidade natural, um estado transitório cíclico, mas que, inevitavelmente, afeta o livre arbítrio. Se a Nietzsche essa dualidade serve simbolicamente para elaborar uma crítica à moral ocidental e encontrar uma fenda no verniz da ordem apolínea, em Molina aparece como fragilidade da natureza humana e como condicionamento físico a ter em conta nas regras do julgamento moral. No entanto, no contexto da reflexão molinista, interessa principalmente essa passagem do sono à vigília, esse hiato de razão limitada e débil, de uma consciência em trânsito entre dois estados, que já possui poder para realizar atos livres em função do prazer associado ao objeto, ainda que sem um uso completo da razão, por força dos limites físicos. Seja como for, será nesse caso determinante a condução moral habitual da ação no estado de vigília, pelo que se torna manifestamente importante a inclinação do hábito ${ }^{27}$.

Além dos estados apontados, há outras condições pelas quais também os adultos podem ver limitado o seu uso de razão, como acontece quando a ação requer mais tempo e maior preparação ${ }^{28}$. O estado de ignorância do adulto é posto em certa medida em igualdade com as demais situações. Não suspende a liberdade da vontade, que pode ainda assim realizar atos livres, mas afeta o uso da racionalidade e o discernimento moral, desresponsabilizando o agente.

Mais além da ignorância em termos momentâneos e transitórios, essa pode colocar-se pela condição natural, assumindo-se como um aspeto fundamental com implicações assinaláveis. Para o jesuíta espanhol, a ignorância é a condição natural do ser humano, associada à debilidade das forças da razão e ao seu desenvolvimento possível. Se tivermos em conta que o fim último do ser humano é a elevação sobrenatural a Deus,

${ }^{26}$ Cf. NIETZSCHE, Friedrich, $A$ origem da tragédia, tradução de Álvaro Ribeiro. Lisboa: Guimarães Editores, 1974.

27 Cf. MOLINA, Luis de, Concordia, d. 2, 8: “[...] iis soleat qui a somno ad vigiliam transeunt neque integre neque perfecte ratione liberam, sed eo modo partim libera et partim ligata [...]".

28 Cf. MOLINA, Luis de, Concordia, d. 2, 7 e 10. 
esse ponto de partida natural pode comprometer a realização dessa finalidade. De fato, Molina não aceita que haja um desejo natural de Deus e, por isso, essa possibilidade não está inscrita por natureza na criatura, pelo que o ser humano pode passar toda a sua vida sem dar sequer com a notícia de haver Deus ou da redenção em Cristo ${ }^{29}$. Exatamente pelo caráter sobrenatural desse conhecimento, ele não é evidente e claro como as coisas que se apresentam à razão na ordem natural ${ }^{30}$. A transcendência que supõe a revelação exige um trabalho de transmissão do conhecimento para que chegue ao maior número possível de seres humanos. Esse é o sentido profundo da atividade missionária. A ignorância relativamente ao conhecimento sobrenatural, aos mandamentos e preceitos divinos e, consequentemente, à importância do seu cumprimento faz com que o agente nessa situação existencial seja inimputável em termos morais. A ignorância constitui um limite à ação moral e ao mérito ou culpa associados.

Tendo em conta essas diversas situações existenciais, nas quais o ser humano não se encontra no mesmo nível de possibilidades do que quando pode usufruir do alcance profundo da faculdade de livre arbítrio, devemos ressalvar que também nunca cai ao nível dos animais ou dos restantes agentes naturais ${ }^{31}$. Molina chega a defender uma certa forma de liberdade nos animais ${ }^{32}$, entendida como vestigium libertatis, mas as suas possibilidades são sempre inferiores na escala de perfeição àquelas de que dispõe o ser humano mesmo em condições limitantes.

Posto isio e tendo em conta a limitação subjacente a esses estados, é importante assinalar a presença no autor de uma determinada ideia otimista de progresso. Molina sublinha a impossibilidade de se evitarem essas limitações de modo imediato. Nos casos aludidos, à exceção do sono, não se aponta a cessação dos condicionamentos de modo súbito, mas valoriza-se bastante essa progressão na direção de uma maior integridade da faculdade racional e das suas possibilidades. É relevante o lugar de destaque que é dado à educação e à medicina,

${ }_{29}$ Cf. MOLINA, Luis de, Concordia, d. 7, 2.

30 Sobre a questão da não evidência da existência de Deus, cf. Queralt, Antonio, Libertad humana en Luis de Molina. Sus elementos constitutivos y posibilidades en un orden natural, op. cit., p. 60ss.

31 Cf. MOLINA, Luis de, Concordia, d. 47, 5.

32 Cf. MOLINA, Luis de, Concordia, d. 47, 5. Cf. também REBALDE, João, "Animal Freedom in Luis de Molina's Concordia", in: OLIVEIRA E SILVA, P. (ed.), Scientia de anima. Studies on Aristotle's De anima commentaries from Islam to the $16^{\text {th }}$ Century Portuguese Universities - Mediaevalia: Textos e Estudos 33, Porto: Faculdade de Letras da Universidade do Porto, 2014, p. 173-200; BRETT, Annabel S., Changes of State: Nature and Limits of the City in Early Modern Natural Law, p. 45ss; MOLINA, Luis de, On Divine Foreknowledge - Part IV of the Concordia, Translation and Notes by Alfred J. Freddoso, New York: Cornell University, 1988, p. 89, especialmente a nota 11. 
esperando dessas artes resultados positivos progressivos. A educação é particularmente valorizada no âmbito da limitação colocada pela infância. A criança desenvolve progressivamente as suas capacidades e os seus conhecimentos, avançando na direção de uma mais completa faculdade de julgar e de discernimento moral. Não se trata apenas do desenvolvimento natural fisiológico e da experimentação continuada das coisas, mas de uma escultura cultural propiciada pelo educação e pela inserção no conjunto dos outros seres humano ${ }^{33}$. O trabalho de esculpir o ser da criança através da educação e do ambiente cultural é progressivo e não pode ser imediato. Mas, é esse processo educativo e cultural que permite potenciar o desenvolvimento das capacidades e competências racionais que facultam o discernimento profundo e completo do bem e do mal morais, mais além do simples conhecimento associado à utilidade e ao prazer que está desde logo presente na infância, relacionando-se com o desenvolvimento último possível do ser humano, orientado à salvação e à visão beatífica de Deus. No entanto, é do grau mais simples da experiência de bem e mal ligada à utilidade e prazer que se progride para o mais complexo de um conhecimento completo de bem e mal morais ${ }^{34}$. A educação e o modo como se conduz o trajeto pedagógico da criança são, assim, determinantes desse processo construtivo da moralidade e do desenvolvimento espiritual ${ }^{35}$.

Se, nas crianças, o papel da educação é fundamental, para Molina também é de extrema importância a educação dos adultos. A ignorância natural impõe-se como uma limitação fundamental, já que é um obstáculo ao discernimento e desenvolvimento espiritual humano, pelo que também a esse nível é determinante um trabalho educativo e de missão religiosa que possa transmitir e testemunhar as verdades da revelação. Além disso, esse trabalho permite também alicerçar o hábito da moralidade, contribuindo para a repetição da ação tornada hábito. O hábito é fundamental enquanto qualidade de ação para onde tende o agente. A tendência é crucial quando está em causa algum condicionamento do uso da razão, porque pode contribuir para evitar males, mesmo que aquele que os pratique se encontre em estados que limitem as forças racionais e não possa ser responsabilizado moralmente pelas suas ações.

Se no caso da dupla face do sono e da vigília já sublinhamos a importância do entremeio entre ambos os estados, que compreende essa passagem natural para a possibilidade do uso completo da faculdade racional e do discernimento moral, no caso da demência o papel principal

33 Cf. MOLINA, Luis de, Concordia, d. 2, 12.

${ }^{34}$ Cf. MOLINA, Luis de, Concordia, d. 2, 12.

35 Em Molina, o papel fundamental da educação no desenvolvimento espiritual relaciona-se proeminente e diretamente com o papel da Igreja. 
é o da medicina, cujos cuidados podem contribuir para a superação da limitação. Molina enfatiza esse processo terapêutico e curativo que não pode operar instantaneamente, mas que supõe resultados progressivos, em que aos poucos o demente pode recuperar-se da sua situação e voltar a fazer um pleno uso das potencialidades da faculdade racional e do livre arbítrio.

Tendo em conta as posições defendidas por Molina, parece consequente que o processo educativo se alargue a todo o ser humano, que, de um modo ou de outro, sempre encontra na ignorância e na debilidade limitações da sua capacidade de discernimento e do desenvolvimento da estrutura de racionalidade. Devemos ter em conta que o processo educativo está intimamente relacionado e referido ao possível desenvolvimento espiritual do ser humano, relativamente ao qual se pode encontrar em diferentes níveis. Essa relação estabelece uma definição cuidada do sentido da educação, do papel do educador e da sua finalidade. $\mathrm{Na}$ filosofia de Molina, essa questão coloca-se decisivamente. O progresso do desenvolvimento da faculdade da razão e a sua repercussão sobre a completa disponibilidade do livre arbítrio implica toda uma capacidade e possibilidade diferenciadora, que se encontra sempre ordenada ao referente último que é o amor e a salvação em Deus e a mediação em Cristo. O ser humano encontra-se nesse caminho, em diferentes níveis dele, sempre em um processo de peregrinação ${ }^{36}$.

\section{Referências}

AGOSTINHO DE HIPONA. "La ciudad de Dios", v. I-II. In: Obras completas de San Agustín. Ed. bilingue, tradução de Santos Santamarta del Rio e Miguel Fuertes Lanero. Madrid: Biblioteca de Autores Cristianos, 1988. Tomos XVI-XVII.

BRETT, Annabel S. Changes of State: Nature and Limits of the City in Early Modern Natural Law. Princeton: Princeton University Press, 2011.

MOLINA, Ludovicus. Liberi arbitrii cum gratiae donis, divina praescientia, providentia, praedestinatione et reprobatione concordia. Editionem criticam curavit Iohannes Rabeneck. Oniae - Matriti: Collegium Maximum S. I. - Soc. Edit. "Sapientia", 1953.

MOLINA, Luis de. Concordia del libre arbitrio con los dones de la gracia y con la presciencia, providencia, predestinación y reprobación divinas. Introdução e tradução de Juan Antonio Hevia Echevarría. Oviedo: Fundación Gustavo Bueno, 2007.

. On Divine Foreknowledge - Part IV of the Concordia. Introduction, translation, and notes by Alfred J. Freddoso. New York: Cornell University, 1988.

NIETZSCHE, Friedrich. A origem da tragédia. Tradução de Álvaro Ribeiro. Lisboa: Guimarães Editores, 1974.

36 Cf. MOLINA, Luis de, Concordia, d. 2, 5. 
OCAÑA GARCÍA, Marcelino. Molinismo y libertad. Córdoba: Publicaciones Obra Social y Cultural Cajasur, 2000.

QUERALT, Antonio. "Libertad humana en Luis de Molina. Sus elementos constitutivos y posibilidades en un orden natural". In: Archivo Teológico Granadino (Madrid Granada), 38 (1975), p. 5-155; 39 (1976), p. 5-100.

REBALDE, João. "Animal Freedom in Luis de Molina's Concordia". In: OLIVEIRA E SILVA, P. (Ed.). Scientia de anima. Studies on Aristotle's De anima commentaries from Islam to the $16^{\text {th }}$ Century Portuguese Universities - Mediaevalia: Textos e Estudos 33. Porto: Faculdade de Letras da Universidade do Porto, 2014, p. 173-200.

STEGMÜLLER, Friedrich. Neue Molinaschriften. Münster: Verlag der Aschendorffschen Verlagsbuchhandlung, 1935 (Beiträge zur Geschichte der Philosophie und Theologie des Mittelalters, Band 32).

THOMAS DE AQUINO. Opera Omnia. Iussu impensaque Leonis XIII P. M. edita. Roma: Polyglotta, 1888ss.

\section{Endereço postal:}

João Rebalde

Gabinete de Filosofia Medieval

Faculdade de Letras da Universidade do Porto

Via Panorâmica, s/n

4150-564 Porto, Portugal

Recebimento: 02/04/2014

Aceite: $12 / 05 / 2014$ 